\title{
Influence of Partner Characteristics and Relational Capital on the Success of Business/Nonprofit Organization Partnerships
}

\author{
María Jesús Barroso-Méndez $\mathbb{D D}^{1},{ }^{1}$ Clementina Galera-Casquet, ${ }^{2}$ Víctor Valero-Amaro, ${ }^{1}$ \\ and María Teresa Nevado-Gil ${ }^{3}$ \\ ${ }^{1}$ Department of Business Management and Sociology, School of Industrial Engineering, University of Extremadura, \\ Badajoz 06006, Spain \\ ${ }^{2}$ Department of Business Management and Sociology, Faculty of Economics and Business, University of Extremadura, \\ Badajoz 06006, Spain \\ ${ }^{3}$ Department of Financial Economics and Accounting, Faculty of Business, Finance and Tourism, University of Extremadura, \\ Cáceres 10071, Spain
}

Correspondence should be addressed to María Jesús Barroso-Méndez; mjbarroso@unex.es

Received 28 March 2020; Revised 2 July 2020; Accepted 21 October 2020; Published 4 November 2020

Academic Editor: Émile J. L. Chappin

Copyright (c) 2020 María Jesús Barroso-Méndez et al. This is an open access article distributed under the Creative Commons Attribution License, which permits unrestricted use, distribution, and reproduction in any medium, provided the original work is properly cited.

\begin{abstract}
The 2030 Agenda for Sustainable Development is the largest framework of global cooperation for human and environmental development on a global scale. This framework requires new responses in the social and political spheres. To a large extent, these can come from different economic and social sectors working together to create synergies that will allow quantitatively significant progress to be made towards the United Nations' Sustainable Development Goals (SDGs). Because of that, in the last few decades, the number of cross-sector social partnerships, and, in particular, partnerships between businesses and nonprofit organizations (NPOs), has increased enormously. However, despite their importance, a large proportion of these partnership processes have been unsuccessful due to the different characteristics of the partners and the relational complexity involved in the multiple factors that affect the collaboration over time. In this regard, the business-NPO literature has stressed the importance of improving the existing understanding of the main factors which favour a partnership's success as well as the interrelationships among those factors. Following different theoretical perspectives used mainly in the context of business-to-business collaborative relationships, the authors test how partner characteristics indirectly influence the success of the partnerships through relational capital. The results, based on a sample $(n=102)$ of Spanish businesses in collaboration relationships with NPOs, show that partner characteristics (shared values and resource complementarity) help in the formation of relational capital (trust, information sharing, and commitment), and that this positively influences the success of such partnership processes (achievement of objectives and satisfaction of the partners).
\end{abstract}

\section{Introduction}

The 2030 Agenda for Sustainable Development is a plan for action that emerged from the commitment of Member States of the United Nations to ensure the protection of people and the environment and to foster sustainable development.

On 25 September 2015, 193 countries approved 17 sustainable development goals (SDGs) with the commitment to meet them by 2030. The goals pursue equality between people, protecting the planet, and ensuring prosperity. They represent the greatest global challenge in history to promote and give incentive to human and environmental development on a global scale. The 17 objectives leave few areas of work without coverage and set goals in all dimensions of the fight against poverty, the reduction of inequalities, the brake on climate change, the conservation of natural environments and species, the construction of healthy and sustainable life environments, respect for human rights, and the construction of new relationships between countries and actors. 
This ambitious framework for action requires new and more complex responses, innovations in the social and political spheres to advance the measures' effectiveness, and solutions that avoid simplicity in the face of these serious and persistent problems. And a good part of this innovative response can undoubtedly come from different economic and social sectors working together, from alliances between different actors, both public and private, that contribute to achieving synergies whose high impact value will enable quantitatively significant results to be achieved in the goals set out by the United Nations.

As a result, in the last few years, the number of crosssector social partnerships, and, in particular, partnerships between businesses and nonprofit organizations (NPOs), has increased enormously [1].

Business-NPO partnerships can be conceptualized as complex systems aimed at addressing social challenges which are mutually important for both partners [2] by taking advantage of their combined resources and always trying to make use of each partner's particular strengths $[2,3]$. However, despite their importance, a large proportion of these partnership processes have been unsuccessful $[4,5]$, an already evident tendency in business-to-business (B2B) collaborations, i.e., alliances involving a single sector [6]. One reason for the difficulties in developing successful partnership processes is that these types of agreements are set up between organizations of quite diverse nature, with different values, resources, and objectives [7-9]. Indeed, it is of vital importance to avoid collaboration agreements with partners who do not share a good level of "strategic fit" [10]. Another reason is the relational complexity that comes from the multiple factors that affect any collaboration over time [11-13]. Numerous authors have argued that, to arrive at a comprehensive understanding of how these partnerships can work better, it is necessary to examine the main factors leading to success and the connections between them $[7,10,14,15]$. However, there has as yet been little attention paid to the attribution of cause-effect relationships in this context [5]. Indeed, the roles that distinguish each success factor are still to be identified [15], and the individual contributions of these factors to partnership success are unclear. All these challenges have had an influence on what methods researchers in this field have applied. Most of the empirical data have come from studies that are purely qualitative, and nearly all have been case studies [5, 16-18].

The present article is in response to calls for there to be further development of theoretical aspects in research on cross-sector alliances [7] and for the results to be capable of generalization. It is aimed at contributing the body of quantitative studies that have been developed recently which use data from large samples that are cross-sector specific to analyse those factors which affect partnership outcomes $[5,12,16-20]$. This research draws on quantitative and qualitative studies that have considered the characteristics of both the partners and the collaboration relationship itself as appropriate for the analysis of the partnership's success $[1,7,10,13,19,21,22]$. Specifically, we contribute to the cross-sector social partnerships literature on success factors by connecting the characteristics of the partners to those of the relationship and assess these factors' contribution to partnership success. Therefore, we identify the role of different factors that directly and indirectly affect partnership success. To the best of our knowledge, this is the first empirical study to demonstrate the role of these factors in improving the success of business-NPO partnerships.

In the sections that follow, we shall present our study framework, define the variables that make up each of its elements, and analyse the relationships that exist between each of these variables. Following a literature review and presentation of hypotheses, we describe our methods and discuss our findings within the context of the existing literature, followed by the main conclusions and the study's theoretical and practical implications.

\section{Literature Review and Hypotheses}

Previous business-NPO partnership studies have focused on the analysis of factors that can favour the success of such partnerships. In general, success factors can be classified into two levels of analysis. On the one hand, the literature has identified success factors during the association formation phase that are related to the characteristics of the participating members [1, 7-10, 22, 23]. In this regard, the vast majority of these authors have indicated that firms and NPOs should seek partners that seem to have a good fit for the said association process, in particular stressing the importance of a "strategic fit between partners," which implies a process of alignment of values, beliefs, and resources [10]. On the other hand, other authors have highlighted success factors during the collaboration implementation phase that are related to characteristics of the relationship itself, which they call "relational factors" [7, 11-13, 18, 21, 24-26]. According to these authors, the implementation of an adequate selection process is not the only requirement for achieving success in an association process. The relationship between the partners must also be properly managed [25] in order to understand the set of continuous interactions that take place within the association [24]. In short, it is about knowing those elements that characterize the relationship between the partners, and it is being essential to analyse relationship attributes such as commitment, i.e., a long-term commitment to the relationship, dedicating all the necessary resources to it; trust, i.e., the security that a partner achieves regarding the integrity and response of its counterpart; and the mutual exchange of information.

Nonetheless, despite the important role of these factors, the extent to which each of them contributes to the success of the partnership has not yet been examined systematically within the business-nonprofit context. Indeed, businessnonprofit theory is still principally based on relatively few observations. While these may hold in particular cases, they are insufficient to underpin generalizable hypotheses which instead need supporting evidence from larger samples.

This research gap has been approached from different theoretical perspectives, mainly in the field of collaborative 
relationships between firms. In synthesis, it is possible to identify three currents of research in the literature on success in business partnership processes:

(i) Structural current. The focus of this current has been on the success factors that take place during the partnership's formation phase. These factors are related to partner characteristics and therefore to an appropriate partner selection process [27, 28].

(ii) Interactive current. The focus of this current is on the success factors that take place during the partnership's implementation phase, i.e., during the process of interaction between the partners [29]. This line has argued that the relational capital, or the set of psychological aspects of a collaboration that find expression in relational factors, is critical to achieving greater success in the partnership [30].

(iii) Synthetic current. This current has combined the structural and interactive perspectives [31-34]. In particular, the authors who support this view argue that the structural factors do not affect the success of partnership directly but rather indirectly through the relational factors of the relationship.

The present study follows the synthetic theoretical perspective as being the most current, inclusive, and integrative of the three and, therefore, views relational capital as a mediatory variable. In this way, our empirical study, set in the context of one European country, investigates how characteristics of the business and the NPO affect the success of their partnership through the psychological aspects that help to create relational capital within that partnership (see Figure 1).

\subsection{Relationships between Partner Characteristics and Rela-} tional Capital. Partner characteristics are fundamental since they help in the formation of relational capital or the psychological aspects of a partnership process [31]. Numerous authors $[7,10]$ have commented that the identification of shared values between the partners, expressed, for example, through common interests towards the resolution of the social problem addressed, turns out to be key to avoid the appearance of conflicts [10] and, therefore, to guarantee the success of the said association processes. Other authors, however $[1,8]$, have stated that resource complementarity plays a key role within the characteristics that each partner must have when participating in a strategic alliance process. Accordingly, in our study, we believe it appropriate to follow this line and introduce these two key variables into our model. Next, we conceptualize each of them and set out the links that we shall validate empirically.

Resource complementarity represents the degree to which each organization provides idiosyncratic resources the other lacks and therefore fills the other organization's needs $[35,36]$. Following this conceptualization, in our study context, we consider this construct to be the measure to which each partner, the business, and the NPO contribute unique resources to the collaboration relationship.
Complementary resources can motivate the two partners to collaborate because together they can produce outcomes unattainable when working alone [36]. Therefore, in accordance with the literature on B2B collaborations, partners with distinctive resources are more likely to be interested in creating relational capital by engaging in trustworthy acts that decrease their vulnerability to each other [37] and by maintaining open and participative lines of communication [31, 32]. Accordingly, we posit the following research hypotheses:

\section{H1: resource complementarity influences trust directly and positively.}

H2: resource complementarity influences information sharing directly and positively.

Shared values can be conceptualized as "the extent to which partners have beliefs in common about what behaviours, goals, and policies are important or unimportant, appropriate or inappropriate, and right or wrong" [38] (p. 25). Being beliefs, shared values are therefore cognitive in nature [39]. Following this conceptualization, in our research context, the construct shared values could be defined as "the level at which a firm and an NPO share within their association process a set of analogous values on different aspects (for example, in terms of beliefs about the importance of different social problems or issues and necessary ethical patterns of behaviour)."

The shared values, which facilitate a sense of unity in the relationship, are likely to foster relational capital building behaviour in the partners [32]. According to the literature on B2B alliances, when partners perceive that their counterpart has chosen the appropriate actions, they will be willing to share more information $[31,32]$ and to increase their level of trust [40-42]. This is especially important in our research context where cultural differences between partners are particularly relevant. Following those authors, we therefore posit the following two hypotheses:

\section{H3: shared values influence trust directly and positively.}

H4: shared values influence information sharing directly and positively.

\subsection{Relational Capital: Relationships among Its Key Variables.} The relational capital-psychological aspects of a collaboration that find expression in relational factors-is key to improving the success of the partnering processes. Many authors have highlighted that, among the different factors that should characterize the collaboration relationship itself, trust between partners is transcendental [1,43] since its presence helps to overcome antagonisms and allows shared goals to be developed. Likewise, Glasbergen [44] has stressed that the presence of trust can make it less likely for there to be perceptions of vulnerability and risk in the relationship. On the contrary, other authors [14, 15, 17, 45] have suggested that commitment is a further factor that can improve the partners' interactions and hence the partnership's success because of the affective and emotional bonds that it create [17]. Similarly, various studies [7, 10, 26] have noted 


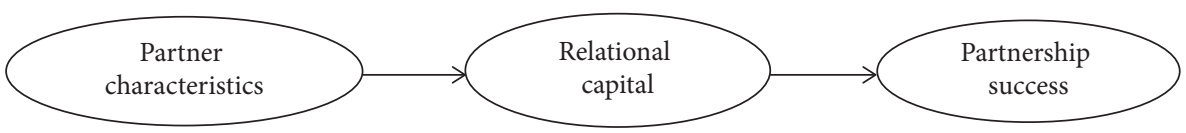

Figure 1: Study framework.

that information sharing can improve the interaction between partners as long as the shared information is valuable to both partners, an example of such information being know-how. In our opinion, these three factors must coexist for relational capital to effectively exert a positive influence on success. Thus, the relational capital in our model will be formed by these three relational factors. Next, we discuss each of them and propose the links that we will validate empirically.

2.2.1. Commitment. Within this literature, one can find numerous definitions of this construct. Anderson and Weitz [46] (p. 191) argued that the essence of commitment is stability and sacrifice and, on this basis, defined this construct as "the desire to develop a stable relationship, a willingness to make short-term sacrifices to maintain the relationship, and a confidence in the stability of the relationship." This definition is similar to that provided by Morgan and Hunt [38] (p. 23): "commitment to the relationship is defined as the exchange partner's belief that the current relationship with the other partner is so important as to guarantee their utmost efforts to maintain it; that is, the committed partner believes that their relationship is very valuable, trying to ensure that it is maintained indefinitely." Recently, Zhang et al. [47] have defined engagement as "the enduring desire to maintain a valued relationship in the future." As can be seen in the set of definitions presented, the literature has mainly mentioned the existence of two components within the commitment construct $[48,49]$ : affective commitment, which reflects attachment due to liking and identification, and calculative commitment, which expresses attachment due to instrumental or economic reasons. Following these works, especially that of Morgan and Hunt [38], in our study context, the construct of commitment could be conceptualized as "the extent to which the business partner perceives that his relationship with the NPO is so valuable as to ensure at all times its best efforts in order to maintain it over time."

2.2.2. Trust. Within the literature, one can find multiple definitions of this construct as well. Based on Anderson and Narus [50] (p. 45), trust can be defined as "the belief of the firm that the other part of the exchange will carry out actions that have positive results for the firm and will not perform unexpected actions that have negative results." Moorman et al. [51] (p. 82), for their part, defined this construct as "the availability to depend on an exchange partner in whom one has confidence." This definition is similar to that provided by Morgan and Hunt [38] (p. 23): "trust exists when a party trusts the veracity and integrity of the exchange partner." Based on a meta-analytic study, Geyskens et al. [52] (p. 225) mentioned that most of the studies present up to that point had defined trust as "the extent to which a partner holds positive expectations that it can rely rationally on the other to do what has been expected to fulfill the partner's specific needs, given its proven capability." As is clear from the above definitions, the literature has mentioned the existence of two components within the trust construct $[53,55]$ : a cognitive element, related to the reliability of the exchange partner, commonly called "honesty" or "credibility," and another behavioural, related to the motivations or intentions of the exchange partner, called "benevolence." Following this distinction, in our study context, the trust construct could be conceptualized as "the degree to which the firm believes that its partner, in this case, the NPO, is credible and benevolent."

2.2.3. Information Sharing. Within the literature, most authors have defined the exchange of information as the formal and informal sharing of timely information between partners [50] in order to coordinate their tasks [56], reduce the risk caused by asymmetry and incomplete information, and solve problems of internal governance [57]. Information sharing includes exchanging data, objectives and goals, and knowledge of conflicts or changing situations [39]. Following this conceptualization, in our study context, the construct of information sharing could be conceptualized as "the mutual exchange of valuable information between the firm and its nonprofit partner."

In the literature on $\mathrm{B} 2 \mathrm{~B}$ collaborations, there seems to be a consensus on the different links existing between the components of relational capital. On the one hand, most studies consider the variable trust to be an antecedent of commitment [17, 41, 58-61] because, without trust, neither of the partners would accept the risk of committing themself to the relationship [62]. And, on the other hand, numerous authors have noted that information sharing helps build commitment by providing partners with a mechanism for resolving disputes and aligning expectations and perceptions $[32,46]$. The present study therefore posited the following hypotheses:

\section{H5: trust affects commitment directly and positively. \\ H6: information sharing affects commitment directly and positively.}

2.3. Relationship between Relational Capital and the Success of a Partnership. The terms "value creation" and "success" are employed interchangeably in most of the business-NPO partnership literature $[3,16,17,19,63,64]$. "Value creation" is the attainment of positive societal and organizational goals as a result of the alliance $[7,15]$. As well as the benefits or positive results that are attained, the literature on businessNPO partnerships stresses that each of the two partners must determine for themselves to what degree the process of 
collaboration has reached the level of performance that it hoped for [25]. In the field of B2B partnerships, it is a common practice to evaluate expectations and outcomes conjointly. Many papers [65-67] have evaluated success in partnerships in terms of two dimensions: the level to which the expected outcomes were actually achieved as a result of the alliance and the partners' satisfaction with those outcomes. We shall therefore consider a business-NPO partnership process to have been successful when it attains the first dimension of expected outcomes of the alliance and the second dimension of the two partners' satisfaction.

Different authors who have focused on B2B collaborations have studied the links between relational capital and the success of the partnership. Recently, Tser-Yieth et al. [32] have demonstrated empirically, through a mediation study, that information sharing and trust influence the success of a B2B relationship through the mediation of commitment. Based on that work and on other research studies which have also proposed and/or provided evidence that commitment directly improves the success of business-business processes $[30,65,67,68]$, we posit the following hypothesis under the assumption that committed partners will work hard enough to make their partnership process succeed:

H7: commitment to the relationship affects the success of partnership processes between businesses and NPOs directly and positively.

2.4. Control Variables. The model incorporates two control variables: the size of the firm and the duration of the collaboration. The size of the firm is used as a control variable because we understand that larger firms have better and greater access to resources, are endowed with better mechanisms for managing and identifying information about their environment, and potentially have better-trained human resources. All this can contribute to the success of any strategy that a firm develops, including an alliance or collaboration with social entities. On the contrary, the duration of the collaboration will provide both the firm and the nonprofit organization with a greater experience of the association, allow them to strengthen their ties with their counterpart, and correct, in the event that the relationship lasts, initial errors or inefficiencies. In this way, the success that can be achieved in the long term may be greater than that achieved in relationships with a shorter time span $[10,25]$.

Figure 2 presents our research framework, showing the variables which form each of the aforementioned elements and the links between them.

2.5. Positing a Rival Model. Taking into account the different perspectives and theoretical approaches applied mainly to the field of relations between firms, we shall compare our hypothesized model with a rival model. The rival model makes three important changes with respect to the proposed model: first, the characteristics of the partners, complementary resources, and shared values influence all the factors that make up the relational capital: trust, commitment, and information sharing; second, the rival model posits that the characteristics of the partners, in addition to influencing the success of the association indirectly through the relational capital, also influence it directly; and third, the rival model proposes that trust and information sharing, in addition to indirectly influencing the success of the association through commitment, also have a direct influence. Therefore, the rival model that is proposed as an alternative investigates all the possible relationships among the latent variables (see Figure 3).

\section{Materials and Methods}

3.1. Study Sample. In 2015, we used a custom-created database of contacts to e-mail an invitation to 657 firms in Spain who had recently been in cross-sector alliances with NPOs for them to participate in a Web-based survey. A maximum of three e-mails were sent to remind the recipients of this invitation. A total of 102 valid responses were finally received, representing a response rate of $15.53 \%$. Table 1 presents the characteristics of the sample.

3.2. Measurements. The survey questionnaire requested the respondents to indicate how far they agreed or disagreed with various statements concerning the constructs of the study. Except for control variables, the item scores were measured on a 7-point Likert scale from 1 (disagree completely) to 7 (agree completely).

The measurements of the two partner characteristics-shared values and resource complementarity-used adaptations of the scales given in MacMillan et al. [40] and Gao and Shi [36], respectively. These variables were modeled as onedimensional composites with a reflective measurement model (mode A) [69] formed by three and two items for shared values and resource complementarity, respectively. The composites are linear combinations of their indicators or dimensions [70]. Hence, the composite's meaning is usually altered when an indicator or dimension is dropped [69] since the facets they represent are different, while, at the same time, strong correlations are far from unusual among indicators and dimensions although they are not requisite [71].

The measurement of trust was adapted from Vázquez et al. [72]. Following their study, we identified two dimensions of trust: credibility and benevolence. The final scale included 12 items. These dimensions were modeled as first-order composites (mode A). However, trust was designed as being a second-order construct. Specifically, trust was modeled as a composite with a formative measurement model (mode B) [69].

Commitment was measured using an adaptation of the scale given in Wittmann et al. [60]. This variable was modeled as a one-dimensional composite (mode A) formed by five items.

Information sharing was also modeled as a one-dimensional composite and measured by seven items adapted from Selnes and Sallis [73].

Similarly, partnership success was designed as being a third-order construct. Specifically, success was modeled as a 


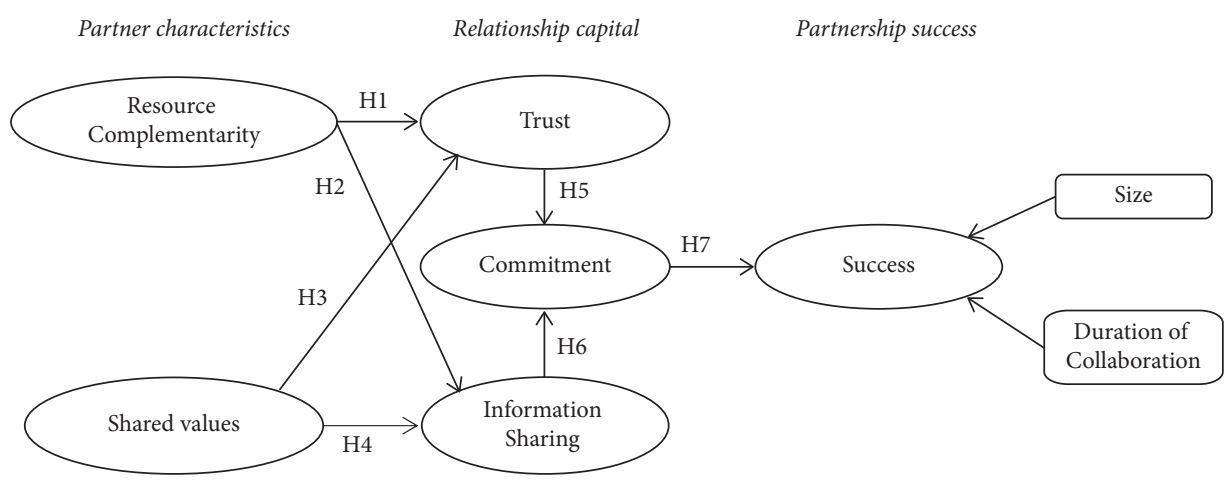

Figure 2: Research model.

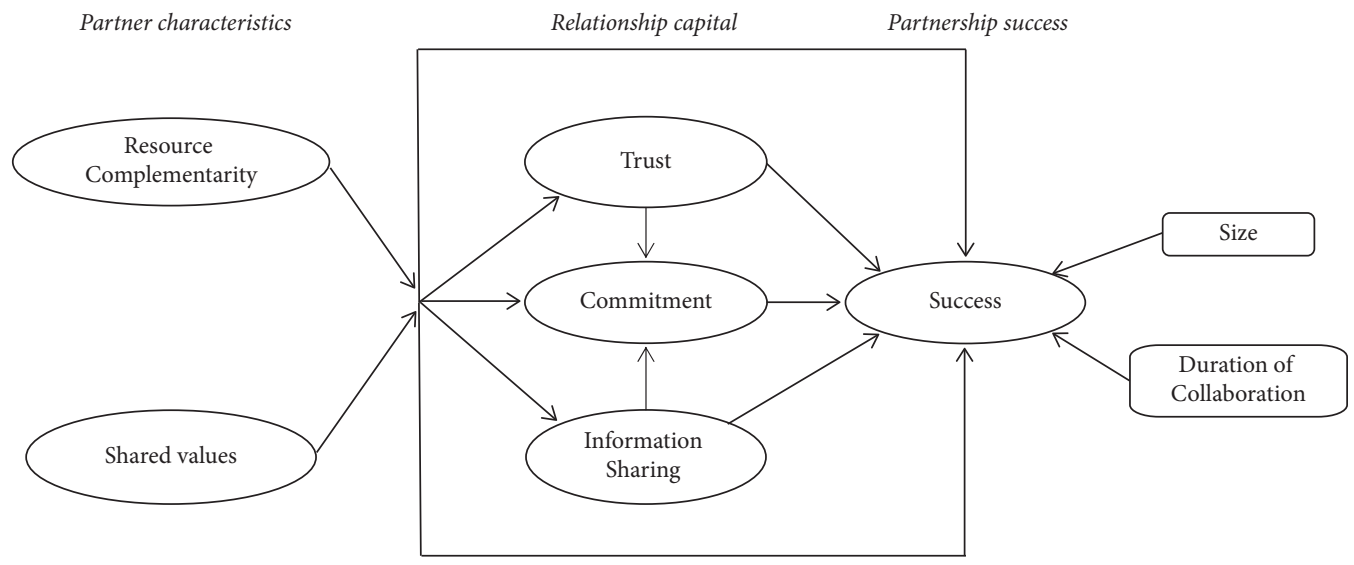

FIgURE 3: Rival model.

TABle 1: Characteristics of the sample.

\begin{tabular}{lc}
\hline Variables & Number of businesses \\
\hline$N$ & 102 \\
$\begin{array}{l}\text { Business size by number } \\
\text { of employees }\end{array}$ \\
$\quad$ SMEs (small and \\
$\quad$ medium sized businesses) \\
$\quad$ Large businesses \\
Business sectors (major standard \\
sector classification) \\
$\quad$ Primary sector \\
$\quad$ Secondary sector \\
$\quad$ Tertiary sector \\
\hline
\end{tabular}

composite with a formative measurement model (mode B) measured by two dimensions [67]: achievement of expected benefits from collaboration and satisfaction.

The measurement of satisfaction used an adaptation of the scale appearing in Cambra and Polo [74] and was modeled as a composite (mode A) formed by two items.

Given the significant differences between benefits accrued in business-business and business-NPO collaborations $[3,40]$ and the lack of previous studies in the literature employing suitable scales, we created and validated a new measurement scale by following the four steps proposed by MacKenzie et al. [75]: (i) Conceptualization of the construct. We defined the construct "achievement of benefits" in the following way: "achievement of different organizational and societal benefits, mutually important for both partners (business and NPO), sought from the partnership process."

(ii) Generation of items. Through an exhaustive review of the literature, we collected different types of benefits with which to create the initial items of our measurement scale (see Table 2). In order to provide content validity to the scale under development, we presented the list of items generated to expert scrutiny. The experts selected were six professionals (3 in businesses and 3 in NPOs) in a first phase and three academics in a second phase. The information received was very useful to eliminate, include, and reformulate the benefits considered in our initial scale. After this step, our new scale comprised 14 indicators.

(iii) Determination of the nature of the measurement model. We decided to use reflective indicators of the construct of interest as measures.

(iv) Validation of the reflective measurement models (we carried out the validation of our scale using our sample of businesses $(N \mathrm{~N}==102))$. A two-step approach was used. Firstly, an exploratory factor analysis (EFA) with varimax rotation was 
performed. Three primary factors were extracted. After an inspection of the items' factor loadings, the factors identified were labeled in the following way: factor 1, "achievement of organizational benefits;" factor 2, "achievement of reputational benefits;" and factor 3, "achievement of societal benefits" (see Table 3 and 4). Second, a confirmatory factor analysis (CFA) was carried out with the Mplus programme. The model's overall fit, after removing three items $(5,9$, and 13$)$, was very satisfactory. The results of the CFA (given in Tables 5 and 6) corroborated the three-factor structure that had been found previously when using EFA.

Thus, eleven items measure the achievement of expected benefits as a multidimensional composite (mode A) comprising three dimensions: achievement of organizational benefits, achievement of reputational benefits, and achievement of societal benefits, which have also been modeled as composites (mode A).

Finally, the control variables were measured as follows. The firm's size was determined in accordance with the number of employees. In particular, following the guidelines of the Enterprise and Industry Directorate-General of the European Commission, we made the following classification: organizations with fewer than 50 employees were designated as small businesses, organizations with 50-250 employees were designated as medium businesses, and those with more than 250 employees were designated as large businesses. The collaboration's duration was measured based on the number of months that a business has been collaborating with an NPO, this being an open field in which the firm could specify the particular duration of their collaboration.

Next, we present a summary table of the measurements used in the study (Table 7).

3.3. PLS Analysis. The method used to test our research model was partial least squares (PLS) path modeling, a type of structural equation modeling that maximizes the variance explained in order to estimate the parameters of the model. It does this by means of a series of ordinary least squares (OLS) regressions for all of the model's endogenous constructs [76]. The primary intention with PLS is causalpredictive analysis, exploring problems which are complex and for which there is little prior theoretical knowledge [76]. In the present work, PLS was chosen for the following reasons: (1) the research model's complexity [77] in both the dimensionality of the constructs (first- and second-order) and the number of (manifest and latent) variables; (2) the subsequent analyses use of latent variable scores [78]; (3) the goal of identifying the key driver constructs for partnership success [79, 80]; and (4) the use of composite models [69]. The PLS analysis was done using the SmartPLS Version 3.3.2 software package.

A PLS analysis comprises two stages [81]: the first is to evaluate the measurement model, and the second is to analyse the structural model. This procedure ensures that one obtains measures of the constructs which are valid and reliable before going on to drawing any conclusions about how constructs may be related [82].

3.4. Common Method Bias. Common-method variance bias $(\mathrm{CMB})$ is a phenomenon that is caused by the measurement method used in a structural equation modeling (SEM) study and not by the network of causes and effects among latent variables in the model being studied [83]. Therefore, CMB could imply a threat for our study if the data obtained do not accurately reflect the real opinion of the surveyed sample. To try to avoid this bias, the recommendations of Podsakoff et al. [84] were taken into account during the drafting of the questionnaire. However, for a greater security, a statistical technique was applied that attempted to detect a potential $\mathrm{CMB}$ situation. This technique consists of performing a full collinearity test based on variance inflation factors (VIFs) [85]. Different authors [85-87] argue that a VIF greater than 3.3 would imply an indication of collinearity, and thus, that the model may be affected by CMB. The present model, with a maximum VIF of 1.938 (Table 8), may be considered free of CMB.

\section{Results}

4.1. Measurement Model. Composites involving reflective indicators (mode A) have to be evaluated in terms of reliability and validity [88]. Firstly, the loadings of the indicators and dimensions (Table 9) were greater than 0.7, meaning that they satisfied the requirement of reliability [89]. For this result, we trimmed some weak items from the commitment (one item) and trust (two items) scales. Although there was one dimension of the "achievement of objectives" construct which also presented a weak loading, we retained it in light of the recommendation of Chin [90] that one should not discard loadings of 0.50 or 0.60 in the initial stages of developing a scale. Secondly, the requisite of construct reliability was satisfied by all the multidimensional constructs and dimensions because none of their composite reliabilities (CR) were less than or equal to 0.7 [91]. Thirdly, the latent variables met the condition of convergent validity given that, as one observes in Table 9, their average variance extracted (AVE) surpassed the recommended threshold of 0.5 [92]. And fourthly, all the variables achieved discriminant validity, which indicates to what extent a given construct is different from the other constructs [93, 94]. According to Fornell and Larcker [92], the values of the square root of AVE ought to be greater than the correlations between the constructs. This requirement was met by all our constructs (see Table 10). Composites involving formative indicators (mode B) were evaluated by analysing the value and sign of the weights and their statistical representativeness and checking for the absence of multicollinearity among the indicators. Since multicollinearity was not detected, none of these indicators was eliminated [95].

4.2. Structural Model. The predictive power was assessed through the analysis of the values of $R^{2}$ (variance explained) of the endogenous constructs [95]. Chin [90] considers $R^{2}$ 
TABLE 2: Individual benefits of businesses and NPOs.

\begin{tabular}{lc}
\hline No. & Benefits \\
\hline 1 & Improving our reputation and image \\
2 & Improving our visibility in society \\
3 & Increasing the motivation of our employees and their identification with our organization \\
4 & Improving the morale of our employees \\
5 & Recruiting and retaining motivated employees \\
6 & Increasing our legitimacy in society \\
7 & Improving our credibility on social priorities \\
8 & Increasing the loyalty of our customers \\
9 & Differentiating ourselves from the competition \\
10 & Improving our economic results \\
11 & Getting a competitive advantage \\
12 & Improving our efficiency \\
13 & Achieving better and more innovative ideas \\
14 & Acquiring resources \\
15 & Changing the management practices of our partner \\
16 & Controlling the management practices of our partner \\
17 & Increasing the number of volunteers \\
18 & Promoting changes in our partner's activity sector \\
19 & Educating employees \\
20 & Addressing a social problem \\
21 & Solving an environmental problem \\
22 & Alleviating a social conflict or tension \\
24 & our partner (skills, experience, technology, and finangort) \\
\hline
\end{tabular}

TABLE 3: Results of the EFA after rotation.

\begin{tabular}{|c|c|c|}
\hline \multirow{2}{*}{ Factor } & \multicolumn{2}{|c|}{ Eigenvalues } \\
\hline & Total & $\%$ variance explained \\
\hline 1 & 4.008 & 28.626 \\
\hline 2 & 2.736 & 19.545 \\
\hline 3 & 2.048 & 14.626 \\
\hline
\end{tabular}

Kaiser-Meyer-Olkin (KMO): 0.837. Bartlett's test of sphericity: 0.000.

TABLE 4: Factor analysis solution.

\begin{tabular}{|c|c|c|c|c|}
\hline & & & Factor & \\
\hline & & 1 & 2 & 3 \\
\hline $\mathrm{AB} 1$ & Improving our visibility in society & 0.340 & 0.836 & 0.036 \\
\hline $\mathrm{AB} 2$ & Being more appreciated by the stakeholders of our organization & 0.284 & 0.825 & 0.207 \\
\hline $\mathrm{AB} 3$ & Improving our public relations & 0.416 & 0.595 & 0.202 \\
\hline AB4 & Increasing the motivation of our employees and their identification with our organization & 0.148 & 0.348 & 0.717 \\
\hline AB5 & Improving our credibility on social priorities & 0.099 & 0.602 & 0.355 \\
\hline AB6 & Increasing the loyalty/commitment of our customers & 0.591 & 0.267 & 0.157 \\
\hline AB7 & Differentiating from the competition & 0.616 & 0.340 & -0.084 \\
\hline AB8 & Getting a competitive advantage & 0.792 & 0.282 & -0.045 \\
\hline AB9 & Achieving better and more innovative ideas, thanks to the support of another partner & 0.631 & 0.353 & 0.378 \\
\hline $\mathrm{AB} 10$ & Acquiring resources through our partner & 0.591 & 0.241 & 0.323 \\
\hline $\mathrm{AB} 11$ & Increasing our number of customers & 0.852 & 0.096 & 0.154 \\
\hline $\mathrm{AB} 12$ & Improving our economic results & 0.859 & 0.102 & 0.157 \\
\hline $\mathrm{AB} 13$ & Strengthening the resources and the capacities of our partner & 0.195 & -0.034 & 0.667 \\
\hline $\mathrm{AB} 14$ & Addressing a social issue & -0.016 & 0.222 & 0.741 \\
\hline
\end{tabular}

Note: we have adapted the wording of the 14 indicators to the specific context of our sample-businesses; items with loadings greater than 0.55 on a factor have been considered "significant" and used in defining that factor. 
TABLE 5: Loadings of the indicators on the three factors considered.

\begin{tabular}{|c|c|c|c|c|}
\hline & & $\begin{array}{l}\text { Achievement of } \\
\text { reputational benefits }\end{array}$ & $\begin{array}{l}\text { Achievement of } \\
\text { organizational benefits }\end{array}$ & $\begin{array}{l}\text { Achievement of } \\
\text { societal benefits }\end{array}$ \\
\hline $\mathrm{AB} 1$ & Improving our visibility in society & 0.866 & - & - \\
\hline AB2 & $\begin{array}{l}\text { Being more appreciated by the stakeholders of our } \\
\text { organization }\end{array}$ & 0.905 & - & - \\
\hline AB3 & Improving our public relations & 0.753 & - & - \\
\hline AB4 & $\begin{array}{l}\text { Increasing the motivation of our employees and } \\
\text { their identification with our organization }\end{array}$ & - & - & 0.977 \\
\hline AB6 & $\begin{array}{l}\text { Increasing the loyalty or commitment of our } \\
\text { customers }\end{array}$ & - & 0.716 & - \\
\hline AB7 & Differentiating ourselves from the competition & - & 0.625 & - \\
\hline AB8 & Getting a competitive advantage & - & 0.764 & - \\
\hline $\mathrm{AB} 10$ & Acquiring resources through our partner & - & 0.704 & - \\
\hline AB11 & Increasing our number of customers & - & 0.811 & - \\
\hline AB12 & Improving our economic results & - & 0.830 & - \\
\hline AB14 & Addressing a social issue & - & - & 0.647 \\
\hline
\end{tabular}

TABLE 6: Correlations among the three factors.

\begin{tabular}{lccc}
\hline & $\begin{array}{c}\text { Achievement of reputational } \\
\text { benefits }\end{array}$ & $\begin{array}{c}\text { Achievement of organizational } \\
\text { benefits }\end{array}$ & $\begin{array}{c}\text { Achievement of societal } \\
\text { benefits }\end{array}$ \\
\hline $\begin{array}{l}\text { Achievement of reputational } \\
\text { benefits }\end{array}$ & 1.000 & - & - \\
$\begin{array}{l}\text { Achievement of } \text { organizational } \\
\text { benefits }\end{array}$ & 0.592 & 1.000 & - \\
Achievement of societal benefits & 0.448 & 0.377 & 1.000 \\
\hline
\end{tabular}

values of $0.67,0.33$, and 0.19 to be substantial, moderate, and weak, respectively. As can be seen in Table 11, in our model, the $R^{2}$ values correspond to moderate for all constructs: success (0.348), commitment (0.585), confidence (0.427), and information sharing (0.343).

The predictive relevance of the endogenous constructs with a reflective measurement model was evaluated using the Stone-Geisser test $\left(Q^{2}\right)$. One observes in Table 11 that all the endogenous constructs of our predictive model have predictive relevance since the $Q^{2}$ values are greater than zero [95].

For the analysis of the path coefficients' significance, a bootstrapping procedure (with 10,000 resamples) was used to generate the standard errors and the $t$-statistics [81]. All the proposed research hypotheses are supported since they exceed the minimum level indicated by a one-tailed Student's $t$-test with $n-1$ ( $n=$ number of resamples) degrees of freedom [78] (see Table 12).

Finally, the model's overall fit was evaluated in terms of the Standardized Root Mean Square Residual (SRMR), which is the root of the mean square difference between the observed and the model-implied correlations [96], and of the Normed Fit Index (NFI), defined as 1 minus the $\chi^{2}$ value of the proposed model divided by the $\chi^{2}$ value of the null model [97]. As one observes in Table 12, the computed value of SRMR was 0.060 , implying that the fit is adequate given that it is below the usually accepted threshold (0.08) for goodness of fit [96]. Also, the value of NFI was 0.733 , and the closer this index is to 1 in its permitted range of 0 to 1 , the better the fit so that again the fit can be considered appropriate.
4.3. Rival Model. Table 13 lists the results for the rival model. This model accounts for $37.1 \%, 64.4 \%, 40.4 \%$, and $40.3 \%$ of the variance in partnership success, commitment, trust, and information sharing, respectively. The $Q^{2}$ values are all positive, supporting the predictive relevance of the model. Of the 13 hypothesized paths, 6 (46.1\%) are supported, but 4 of the 6 added paths that distinguish the rival model from the model proposed in this work are not supported. More importantly, the two hypotheses that posit a direct relationship between characteristics of the partners and success are not supported, which is consistent with the mediating role of the relational capital considered in our proposed model. The two control variables used were not significant. Finally, the SRMR value of the rival model is 0.069 and the NFI is 0.734 so that it does not perform better than our proposed model.

4.4. Assessment of the Predictive Validity. After this evaluation and check of the structural model, and with its predictive power (in-sample prediction) known from the data collected, we analysed the predictive relevance (out-ofsample prediction). Out-of-sample prediction examines whether the model is capable of predicting the behaviour of the dependent variables in situations other than those used for its fit. The out-of-sample procedure followed was that designed by Shmueli and Koppius [98], applying the PLS predict technique implemented in the SmartPLS software $[99,100]$. This technique divides the data sample into $k$ sections and calculates the model parameters with a large proportion (grouping together $k-1$ sections) of the original 
TABLE 7: Measurement scales.

\begin{tabular}{|c|c|c|}
\hline Constructs & Indicators & Source \\
\hline Shared values & $\begin{array}{l}\text { SV1: the values and opinions of our partner are similar to ours } \\
\text { SV2: we respect the values of our partner } \\
\text { SV3: we share a very similar set of values }\end{array}$ & $\begin{array}{l}\text { Adapted from } \\
\text { MacMillan et al. [40] }\end{array}$ \\
\hline $\begin{array}{l}\text { Resource } \\
\text { complementarity }\end{array}$ & $\begin{array}{l}\text { RC1: the two organizations have complementary strengths that are useful to the relationship } \\
\text { RC2: the two organizations contribute necessary but different capabilities to the relationship }\end{array}$ & $\begin{array}{l}\text { Adapted from Gao } \\
\text { and Shi [36] }\end{array}$ \\
\hline
\end{tabular}

TR1: our partner does what they promise

TR2: if our partner detects a problem, they react in an understandable way and try to help us

TR3: our partner does not make false claims

TR4: our partner is reliable and behaves as one would expect them to

TR5: our partner does not keep back critical information that may affect our decisions

TR6: our partner is competent to meet their commitments

TR7: our partner has made sacrifices for us in the past

Trust

TR8: our partner is concerned for our well-being, interests, and future success

TR9: our partner is prepared to provide assistance and support when times are hard

Benevolence

TR10: we feel that our partner is on our side

TR11: our partner does not generally take decisions that are prejudicial to us

TR12: our partner is quite honest and sincere in their relationship with us

IS1: we share information on successful and unsuccessful experiences in the implementation of different social programmes

IS2: we share information related to changes in the needs of the beneficiary population of the programmes that we carry out together

IS3: we share information related to changes in the specific environment of the programmes that we carry out together

Information sharing

IS4: we share information related to new techniques of the implementation of social

Adapted from Selnes and Sallis [73]
Adapted from

Vázquez et al. [72] programmes and new methods or tools for identification and intervention

IS5: we share information of any unexpected problem as soon as possible

IS6: we share information on changes related to our strategies and policies

IS7: we share information that is sensitive for us, such as financial information, know-how, and new developments

CM1: we are very committed to the relationship with our partner

$\mathrm{CM} 2$ : the relationship with our partner is very important to us

Commitment CM3: we intend to maintain our relationship with our partner indefinitely

CM4: we really care about the relationship with our partner

CM5: we think the relationship with our partner deserves our maximum effort to maintain it in the future 
TABLE 7: Continued.

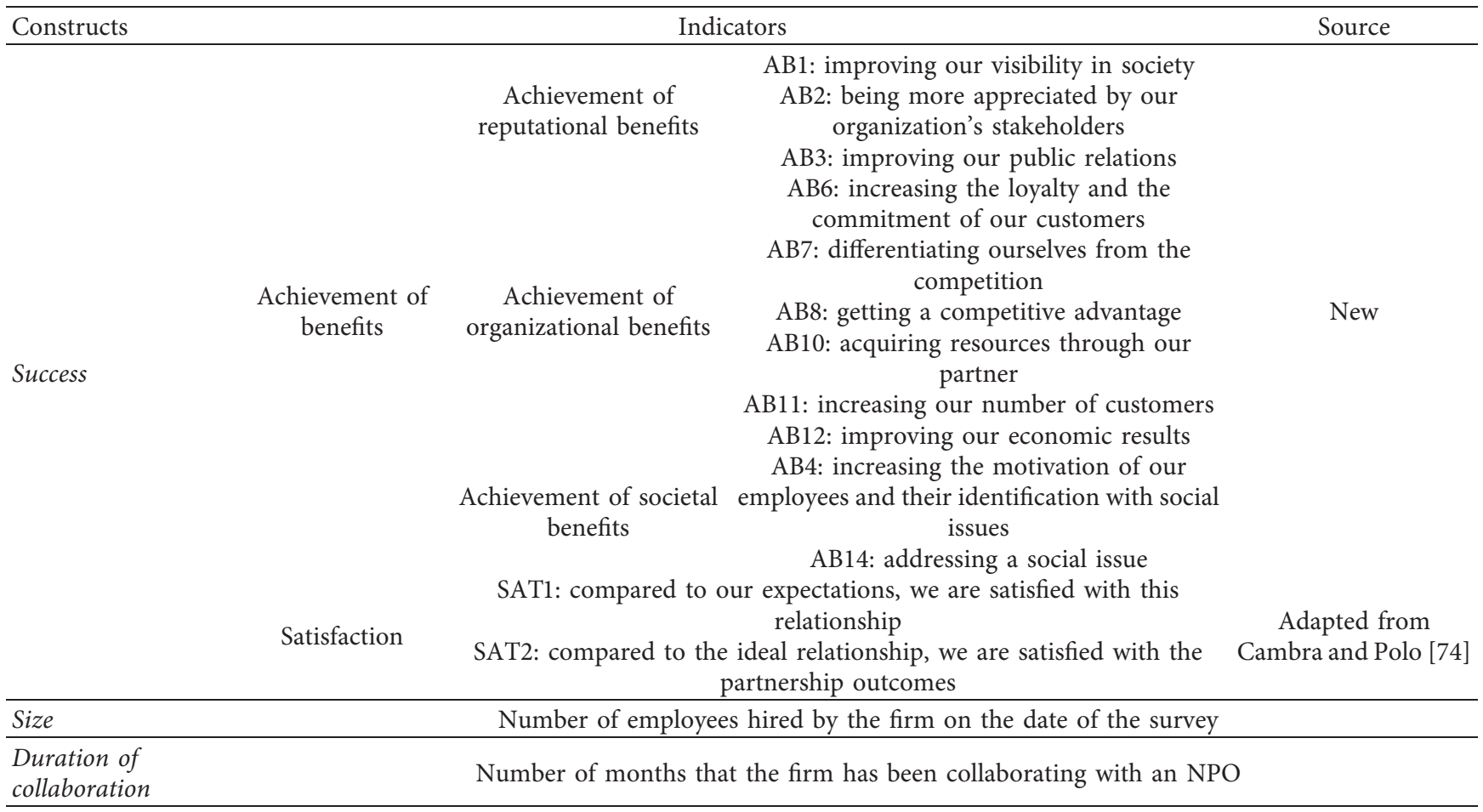

TABLE 8: Full collinearity VIFs.

\begin{tabular}{lccccccc}
\hline Variables & SV & RC & TR & CM & IS & PS & DC \\
VIFs & 1.064 & 1.585 & 1.695 & 1.914 & 1.938 & 1.319 & 1.020 \\
\hline
\end{tabular}

Note: VIFs shown are for all of the latent variables. SV: shared values; RC: resource complementarity; TR: trust; CM: commitment; IS: information sharing; PS: partnership success; DC: duration of collaboration; S: size.

sample (the training sample) and then calculates these parameters again for the rest of the data (the holdout sample). This yields a series of statistics such as $k$-fold cross-validated prediction errors, mean absolute percentage error (MAPE), root mean squared error (RMSE), and mean absolute error (MAE). The software provides two criteria with which to evaluate the predictive relevance of the model $[99,101]$ :

(1) $Q^{2}$ _predict value. This parameter compares the model's prediction errors with respect to the simple predictions made on the basis of the values estimated from the training sample. If $Q^{2}$ is positive, the model's prediction errors are less than the errors that arise from predicting simply using mean values. Therefore, a first evaluation consists of checking that all the $Q^{2}$ values of the model's predictors are positive.

(2) The software generates a linear regression (LM) of all the exogenous indicators of the model to predict each endogenous indicator. Comparing the results of the original model with those obtained with this regression, those of the PLS model should have lower prediction errors (as measured by either the RMSE or the MAE). This analysis is only done for the indicator/dimension level.
We designed this analysis with three sections $(k=3)$ and 10 repetitions. The values of the parameters, ordered into levels of construct, dimension, and indicator, are listed in Table 14.

All the $Q^{2}$ _predict values of the indicators/dimensions of the dependent variables are positive. In particular, therefore, the model has predictive capacity for all four endogenous constructs. Of special interest is the case of the most important of these constructs-success. While success is the least predictable of the four according to their $Q^{2}$ _predict values, it is the most important in the sense that it is the ultimate reason for the very existence of these partnerships. Their whole underlying purpose is to achieve success in the projects the partners undertake together.

The symmetry of the distribution of indicator prediction errors was analysed to determine which measure of error (RMSE or MAE) to use in estimating the indicators' predictive power. Once the error measure to be used has been chosen, it is expected that the difference represented by subtracting the corresponding simple linear regression prediction error from the model error (the column $\Delta$ [PLSLM] in Table 10) will be negative if the model has predictive capacity for that indicator.

As one observes in the table, this technique provides clear evidence for the model's predictive capacity as it is able to 
TABLE 9: Measurement model results.

\begin{tabular}{|c|c|c|c|c|}
\hline Construct/dimension/subdimension & Loading (weight) & CR & AVE & VIF \\
\hline Shared values & - & 0.859 & 0.670 & - \\
\hline SV1: the values and opinions of our partner are similar to ours & 0.841 & - & - & - \\
\hline SV2: we respect the values of our partner & 0.755 & - & - & - \\
\hline SV3: we share a very similar set of values & 0.857 & - & - & - \\
\hline Resource complementarity & - & 0.905 & 0.826 & - \\
\hline $\mathrm{RC} 1$ : the two organizations have complementary strengths that are useful to the relationship & 0.888 & - & - & - \\
\hline RC2. the two organizations contribute necessary but different capabilities to the relationship & 0.929 & - & - & - \\
\hline Trust & - & n.a. & n.a. & - \\
\hline Credibility & $(0.671)$ & 0.885 & 0.607 & 1.832 \\
\hline TR1: our partner does what they promise & 0.761 & - & - & - \\
\hline TR2: if our partner detects a problem, they react in an understandable way and try to help us & 0.792 & - & - & - \\
\hline TR3: our partner does not make false claims & 0.716 & - & - & - \\
\hline TR4: our partner is reliable and behaves as one would expect them to & 0.840 & - & - & - \\
\hline TR6: our partner is competent to meet their commitments & 0.781 & - & - & - \\
\hline Benevolence & $(0.416)$ & 0.897 & 0.636 & 1.832 \\
\hline TR8: our partner is concerned for our well-being, interests, and future success & 0.853 & - & - & - \\
\hline TR9: our partner is prepared to provide assistance and support when times are hard & 0.732 & - & - & - \\
\hline TR10: we feel that our partner is on our side & 0.875 & - & - & - \\
\hline TR11: our partner does not generally take decisions that are prejudicial to us & 0.760 & - & - & - \\
\hline TR12: our partner is quite honest and sincere in their relationship with us & 0.757 & - & - & - \\
\hline Commitment & - & 0.936 & 0.786 & - \\
\hline CM1: we are very committed to the relationship with our partner & 0.914 & - & - & - \\
\hline CM2: the relationship with our partner is very important to us & 0.905 & - & - & - \\
\hline CM4: we really care about the relationship with our partner & 0.898 & - & - & - \\
\hline $\begin{array}{l}\text { CM5: we think the relationship with our partner deserves our maximum effort to maintain it in } \\
\text { the future }\end{array}$ & 0.827 & - & - & - \\
\hline Information sharing & - & 0.941 & 0.696 & - \\
\hline $\begin{array}{l}\text { IS1: we share information on successful and unsuccessful experiences in the implementation of } \\
\text { different social programmes }\end{array}$ & 0.829 & - & - & - \\
\hline $\begin{array}{l}\text { IS2: we share information related to changes in the needs of the beneficiary population of the } \\
\text { programmes that we carry out together }\end{array}$ & 0.878 & - & - & - \\
\hline $\begin{array}{l}\text { IS3: we share information related to changes in the specific environment of the programmes that } \\
\text { we carry out together }\end{array}$ & 0.856 & - & - & - \\
\hline $\begin{array}{l}\text { IS4: we share information related to new techniques of the implementation of social programmes } \\
\text { and new methods or tools for identification and intervention }\end{array}$ & 0.803 & - & - & - \\
\hline IS5: we share information of any unexpected problem as soon as possible & 0.872 & - & - & - \\
\hline IS6: we share information on changes related to our strategies and policies & 0.845 & - & - & - \\
\hline $\begin{array}{l}\text { IS7: we share information that is sensitive for us, such as financial information, know-how, and } \\
\text { new developments }\end{array}$ & 0.752 & - & - & - \\
\hline Success & - & n.a. & n.a. & - \\
\hline Achievement of benefits & $(0.784)$ & 0.801 & 0.579 & 1.366 \\
\hline Achievement of reputational benefits & 0.776 & 0.922 & 0.798 & - \\
\hline AB1: improving our visibility in society & 0.892 & - & - & - \\
\hline $\mathrm{AB} 2$ : being more appreciated by the stakeholders of our organization & 0.913 & - & - & - \\
\hline AB3: improving our public relations & 0.876 & - & - & - \\
\hline Achievement of organizational benefits & 0.597 & 0.915 & 0.645 & - \\
\hline AB6: increasing the loyalty and the commitment of our customers & 0.785 & - & - & - \\
\hline AB7: differentiating ourselves from the competition & 0.671 & - & - & - \\
\hline AB8: getting a competitive advantage & 0.797 & - & - & - \\
\hline AB10: acquiring resources through our partner & 0.745 & - & - & - \\
\hline AB11: increasing our number of customers & 0.904 & - & - & - \\
\hline AB12: improving our economic results & 0.893 & - & - & - \\
\hline Achievement of societal benefits & 0.882 & 0.889 & 0.801 & - \\
\hline AB4: increasing the motivation of our employees and their identification with social issues & 0.919 & - & - & - \\
\hline AB14: addressing a social issue & 0.870 & - & - & - \\
\hline Satisfaction & $(0.337)$ & 0.943 & 0.891 & 1.366 \\
\hline SAT1: compared to our expectations, we are satisfied with this relationship & 0.957 & - & - & - \\
\hline SAT2: compared to the ideal relationship, we are satisfied with th & 0.931 & - & - & - \\
\hline
\end{tabular}

Note: CR: composite reliability; AVE: average variance extracted; VIF: variance inflation factor. 
TABLE 10: Measurement model: discriminant validity.

\begin{tabular}{lccccccc}
\hline & SV & RC & TR & CM & IS & PS & S \\
\hline SV & $\mathbf{0 . 8 1 9}$ & & & & & & \\
RC & 0.483 & $\mathbf{0 . 9 0 9}$ & & & & & \\
TR & 0.631 & 0.476 & n.a. & & & \\
CM & 0.657 & 0.573 & 0.671 & $\mathbf{0 . 8 8 7}$ & & \\
IS & 0.419 & 0.561 & 0.522 & 0.670 & $\mathbf{0 . 8 3 5}$ & & \\
PS & 0.454 & 0.403 & 0.529 & 0.566 & 0.509 & n.a. & \\
S & 0.107 & 0.151 & 0.045 & 0.135 & 0.223 & 0.242 & n.a. \\
DC & 0.108 & 0.090 & 0.021 & 0.076 & -0.010 & 0.058 & n.a. \\
\hline
\end{tabular}

Note: analysis carried out for all of the latent variables. SV: shared values; RC: resource complementarity; TR: trust; CM: commitment; IS: information sharing; PS: partnership success; DC: duration of collaboration; S: size. Fornell-Larcker criterion: diagonal elements (bold) are the square root of the variance shared between the constructs and their measures (AVE). Off-diagonal elements are the correlations between constructs. For discriminant validity, diagonal elements should be greater than off-diagonal elements. n.a.: not applicable.

TABLE 11: Effects on endogenous variables.

\begin{tabular}{|c|c|c|c|c|c|c|}
\hline & & $R^{2}$ & $Q^{2}$ & Direct effect & Correlation & Variance explained (\%) \\
\hline Success & & 0.348 & 0.204 & - & - & 34.8 \\
\hline H7: commitment & & - & - & 0.543 & 0.566 & 30.7 \\
\hline \multirow{2}{*}{ Control variables } & Size & - & - & 0.168 & 0.242 & 4.1 \\
\hline & Duration of collaboration & - & - & 0.002 & 0.058 & 0.0 \\
\hline \multirow{3}{*}{\multicolumn{2}{|c|}{$\begin{array}{l}\text { Commitment } \\
\text { H5: trust } \\
\text { H6: information sharing }\end{array}$}} & 0.59 & 0.451 & - & - & 59.0 \\
\hline & & - & - & 0.441 & 0.671 & 29.6 \\
\hline & & - & - & 0.439 & 0.670 & 29.4 \\
\hline \multicolumn{2}{|c|}{ Information sharing } & 0.344 & 0.224 & - & - & 34.4 \\
\hline \multicolumn{2}{|c|}{ H4: shared values } & - & - & 0.193 & 0.419 & 8.1 \\
\hline \multicolumn{2}{|c|}{$\mathrm{H} 2$ : resource complementarity } & - & - & 0.468 & 0.561 & 26.3 \\
\hline \multicolumn{2}{|c|}{ Trust } & 0.436 & 0.334 & - & - & 43.6 \\
\hline \multicolumn{2}{|l|}{ H3: shared values } & - & - & 0.523 & 0.631 & 33.0 \\
\hline \multicolumn{2}{|c|}{ H1: resource complementarity } & - & - & 0.223 & 0.476 & 10.6 \\
\hline
\end{tabular}

Note: each endogenous construct's variance explained in terms of another latent variable is given by multiplying the $\beta$ coefficient (direct effect) by the correlation of the two variables.

TABLE 12: Structural model results.

\begin{tabular}{|c|c|c|c|}
\hline Hypothesis & Path coefficient & $t$-value & Support \\
\hline H1: resource complementarity $\longrightarrow$ trust & $0.223^{* *}$ & 2.295 & Yes \\
\hline $\mathrm{H} 2$ : resource complementarity $\longrightarrow$ information sharing & $0.468^{* * *}$ & 3.656 & Yes \\
\hline H3: shared values $\longrightarrow$ trust & $0.523^{* * *}$ & 6.634 & Yes \\
\hline H4: shared values $\longrightarrow$ information sharing & $0.193^{*}$ & 1.839 & Yes \\
\hline H5: trust $\longrightarrow$ commitment & $0.441^{* * *}$ & 5.187 & Yes \\
\hline H6: information sharing $\longrightarrow$ commitment & $0.439^{* * *}$ & 5.282 & Yes \\
\hline $\mathrm{H} 7:$ commitment $\longrightarrow$ success & $0.543^{* * *}$ & 6.065 & Yes \\
\hline \multicolumn{4}{|l|}{ Control variables } \\
\hline Size & $0.168^{*}$ & 1.662 & Yes \\
\hline Duration of collaboration & $0.002^{\mathrm{ns}}$ & 0.026 & No \\
\hline
\end{tabular}

NFI: 0.733

${ }^{*} p<0.05 ;{ }^{* *} p<0.01 ;{ }^{* * *} p<0.001$, based on $t(9999)$, one-tailed test, $t(0.05 ; 9999)=1.645, t(0.01 ; 9999)=2.327$, and $t(0.001 ; 9999)=3.092$. ns $=$ not significant.

predict the success of the association processes on the basis of data different from those used for the model's construction.

\section{Discussion}

In general, the proposed model achieves a good fit based on the data collected and supports all of the research hypotheses formulated. In this section, we shall discuss the results for each hypothesis and compare them with those in the literature.

As already mentioned, the hypotheses $\mathrm{H} 1$ and $\mathrm{H} 3$, which represent the possible influence of resource complementarity and shared values on trust, respectively, found empirical support. Therefore, as in the literature on 
TABLE 13: PLS analysis results-structural models.

\begin{tabular}{|c|c|c|c|c|c|c|}
\hline & \multicolumn{3}{|c|}{ Hypothesized model } & \multicolumn{3}{|c|}{ Rival model } \\
\hline & Estimate & $R^{2}$ & $Q^{2}$ & Estimate & $R^{2}$ & $Q^{2}$ \\
\hline Success & & 0.348 & 0.204 & & 0.371 & 0.218 \\
\hline H7: commitment $\longrightarrow$ success & $0.543^{* * *}$ & & & $0.205^{\mathrm{ns}}$ & & \\
\hline Trust $\longrightarrow$ success & - & & & $0.261^{*}$ & & \\
\hline Resource complementarity $\longrightarrow$ success & - & & & $0.035^{\mathrm{ns}}$ & & \\
\hline Information sharing $\longrightarrow$ success & - & & & $0.145^{\mathrm{ns}}$ & & \\
\hline Shared values $\longrightarrow$ success & - & & & $0.071^{\mathrm{ns}}$ & & \\
\hline \multicolumn{7}{|l|}{ Control variables } \\
\hline Size & $0.168^{*}$ & & & $0.143^{\text {ns }}$ & & \\
\hline Duration of collaboration & $0.002^{\mathrm{ns}}$ & & & $0.022^{\mathrm{ns}}$ & & \\
\hline Commitment & & 0.590 & 0.451 & & 0.644 & 0.500 \\
\hline H5: trust $\longrightarrow$ commitment & $0.441^{* * *}$ & & & $0.232^{* *}$ & & \\
\hline H6: information sharing $\longrightarrow$ commitment & $0.439^{* * *}$ & & & $0.340^{* * *}$ & & \\
\hline Resource complementarity $\longrightarrow$ commitment & - & & & $0.118^{\mathrm{ns}}$ & & \\
\hline Shared values $\longrightarrow$ commitment & - & & & $0.317^{* * *}$ & & \\
\hline Information sharing (IS) & & 0.344 & 0.224 & & 0.403 & 0.278 \\
\hline H4: shared values $\longrightarrow$ IS & $0.193^{*}$ & & & $0.012^{\mathrm{ns}}$ & & \\
\hline $\mathrm{H} 2:$ resource complementarity $\longrightarrow$ IS & $0.468^{* * *}$ & & & $0.374^{* *}$ & & \\
\hline Trust & & 0.436 & 0.334 & & 0.404 & 0.328 \\
\hline H3: shared values $\longrightarrow$ trust & $0.523^{* * *}$ & & & $0.487^{* * *}$ & & \\
\hline H1: resource complementarity $\longrightarrow$ trust & $0.223^{* *}$ & & & $0.249^{*}$ & & \\
\hline SRMR & 0.060 & & & 0.069 & & \\
\hline NFI & 0.733 & & & 0.734 & & \\
\hline
\end{tabular}

${ }^{*} p<0.05 ;{ }^{* *} p<0.01 ;{ }^{* * *} p<0.001$ (based on $t$ (9999), one-tailed test). ns = not significant.

TABLE 14: Summary of prediction parameters.

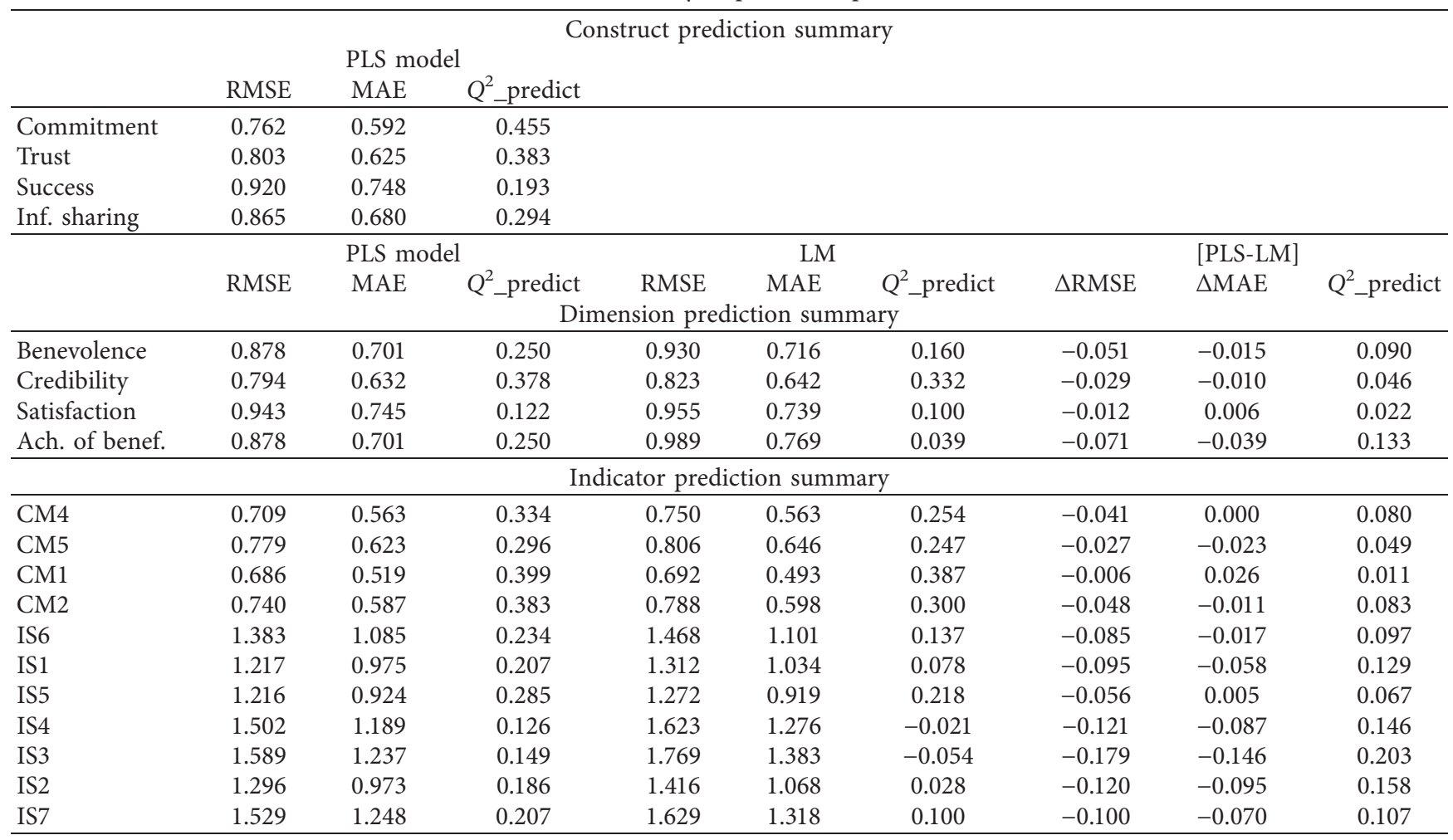

Note: the differences $\triangle \mathrm{RMSE}$ and $\triangle \mathrm{MAE}$ are the prediction error for the PLS model minus that for the simple linear regression model for the two error measures RMSE or MAE, respectively. 
TABLE 15: Measurement of skewness of prediction errors.

\begin{tabular}{lcccc}
\hline & Skewness & Error used & $\Delta[$ PLS-LM] & Predictive power \\
\hline Benevolence & -0.782 & RMSE & -0.051 & Yes \\
Credibility & -0.748 & RMSE & -0.029 & Yes \\
Satisfaction & -0.731 & RMSE & -0.012 & Yes \\
Ach. of benef. & -0.639 & RMSE & -0.071 & Yes \\
CM4 & -0.722 & RMSE & -0.041 & Yes \\
CM5 & -0.687 & RMSE & -0.027 & Yes \\
CM1 & -0.944 & RMSE & -0.006 & Yes \\
CM2 & RMSE & -0.048 & Yes \\
IS6 & -0.576 & RMSE & -0.085 & Yes \\
IS1 & -0.863 & MAE & -0.058 & Yes \\
IS5 & -1.005 & MAE & -0.121 & No \\
IS4 & -1.056 & RMSE & -0.146 & Yes \\
IS3 & -0.815 & MAE & -0.095 & Yes \\
IS2 & -1.067 & MAE & -0.100 & Yes \\
IS7 & -1.129 & RMSE & Yes \\
\hline
\end{tabular}

Note: the difference $\Delta[$ PLS-LM] is the prediction error (RMSE or MAE) for the PLS model minus that for the simple linear regression model.

relationships between businesses [37, 42], we found that both of these factors are positively related to trust, being predictors of it in explaining $43.6 \%$ of its variance. Nonetheless, the shared values factor exerts by far the greater impact on this construct, explaining $33.0 \%$ of its variance. For this, shared values can be regarded as a major antecedent explaining trust, and we might conclude in light of these results that organizations from different sectors which do not share values might be unable to create a climate of mutual trust in any partnership they attempt to undertake. In coherence with other workers [7, 10], our data suggest that it is essential for a business to share similar values and beliefs with its potential nonprofit partners.

The relationships "resource complementarity-information sharing" and "shared values-information sharing," namely, the $\mathrm{H} 2$ and $\mathrm{H} 4$ hypotheses, gave statistically significant results. In this sense, as in the literature on businessto-business relationships [31, 32], we found that both of these factors are positively related to information sharing. However, as before, although together they are also good predictors of information sharing, explaining $34.4 \%$ of its variance, it is one of them, resource complementarity, that exerts by far the greater impact, explaining $26.3 \%$ of that variance. Therefore, resource complementarity can be regarded as a major antecedent of this relational construct. The presence of complementary resources in the partnership, i.e., the existence of a collaboration in which each partner, provides idiosyncratic resources that the other does not have and which are difficult to transfer, and can motivate the partners to facilitate such transfer of resources through a greater sharing of information. In this sense, in coherence with Austin [25] and Rodríguez et al. [8], our results confirm that it is fundamental for businesses to have complementary resources with their nonprofit partners because this situation can produce results which could not have been achieved if each of them had worked individually, with just their own resources.

The relationships «trust-commitment» and «information sharing-commitment», namely, the $\mathrm{H} 5$ and $\mathrm{H} 6$ hypotheses, had statistically significant results. On the one hand, as the business-to-business literature [17, 41, 58-61], we find that trust is positively related to commitment. Trust contributes to commitment through assurance that partners are able and willing to deliver on their promises and abide by the collaborative agreement, and that they will not opportunistically exploit the partnership for their own gain or at the expense of the other party [20]. Trust emerges, in the context of this present research, when businesses have some evidence based on their own experience that their nonprofit partners will behave in predictable ways. On the other hand, as also described in the literature on business-to-business relationships $[32,46]$, we found that sharing information is positively related to commitment. In this way, businessNPO partnerships in which the partners communicate effectively and share critical and "sensitive" information will show a higher level of commitment between themselves than business-NPO partnerships that do not exhibit this information sharing behaviour. Information sharing is important to commitment because it reduces uncertainty and confusion, thereby enhancing coordination and problem solving [20]. Hence, our data confirm that, without trust and information sharing, commitment would be a complex relational factor for the partners. Nevertheless, unpacking this factor's complexity may allow a more structured comprehension of the way that partners might prioritize the resources they have available for the success of their alliance.

The relationship between commitment and success of the partnership, the hypothesis $\mathrm{H} 7$, received statistically significant results in our study context. In this sense, in line with the literature on relationships between businesses $[30,65,67,68]$, we find that commitment is directly and positively related to the success of the partnership. Hence, building on previous business-NPO research which has suggested that characteristics of the partners have a direct impact on partnership success $[1,7-10,22,23]$, this study has shown that commitment is the main relational factor that mediates the relationship between partner characteristics and partnership success. 
Finally, in relation to the control variables included in the model in order to identify other external factors that could explain the success of an association, our results have found no evidence of influence regarding the duration of the collaboration, thus contradicting the arguments of Austin [25] and Austin and Seitanidi [10]. However, there does seem to be a relationship between the size of the firm and the success of the alliance. Therefore, success is not only explained by the characteristics of the partners and the relationship, but one can see that larger firms are prone to achieve greater success in their association processes with NPOs.

\section{Conclusions}

The 2030 Agenda for Sustainable Development has highlighted the fact that cross-sector social partnerships are necessary instruments for the achievement of global development objectives. However, since these are association processes between organizations of very diverse natures, their establishment and development is not easy, and it is essential to know the main factors that may favour their success, as well as the different links existing between them.

This research opens up new research avenues by proposing and empirically validating, through quantitative data, an explanatory and predictive model of the success of the partnership processes between firms and NPOs. Specifically, by introducing insights originating in the huge body of research on relationships between businesses, this study offers empirical evidence on the role of certain key factors and the extent of their contribution to the success of such business-NPO partnership processes. In addition, it has been possible to verify that the model constructed has a high power of predicting the success of business-NPO partnership processes with data or samples different from those used in the present work.

There have as yet been few quantitative studies examining these conceptual propositions in a businessNPO collaboration context. Academics are hence at risk of accepting common assumptions that are actually insufficiently suited to any reflection of this reality. In this sense, the present work on business-NPO partnerships constitutes an addition to the sparse empirical literature on the drivers of the success of those collaborations.

The present results are of relevance for practitioners as well as academics. Theoretically, they contribute to existing knowledge. Firstly, with respect to the literature on cross-sector social partnerships, there has been the test of theory suggested by existing research on which factors that might affect the success of business-NPO partnerships are most suitable to study $[1,13,19,21,22]$. The business-NPO literature has made clear reference to the importance of certain characteristics of the partners and of the collaboration relationship itself for improving the success of such partnering processes. However, the distinctive role of each of these characteristics has not yet been identified [14]. The links between factors remain elusive, and it is unclear how each contributes to partnership success. The present study has demonstrated, on the one hand, that the characteristics of the partners analysed, the complementarity of resources, and shared values directly influence the relational capital and, on the other hand, that the relational capital influences the success of the association processes, both indirectly through trust and information sharing and directly through commitment between the partners. And secondly, the present findings represent a relatively rare set of generalizable results in business-NPO research, adding to the body of quantitative studies that have been developed recently which use data from large samples that are cross-sector specific in order to measure the factors which influence partnership outcomes [5, 12, 16-20].

In addition to the above relevant implications, there naturally emerge from this study several recommendations to business managers who are responsible for the development of collaborative relationships with NPOs. First, we recommend that if they wish to improve the relational capital of their collaborations, they should critically assess the collaborative fit between their organization and its potential nonprofit partners before proceeding to negotiations about an actual collaboration agreement. Such decisions should not be rushed [20]. Therefore, managers need to explore the entire spectrum of available options, either by working to enhance their current proven contacts or by looking for new ones [102] and selecting those NPOs whose resources and values fit well with those of their own firm. This screening process will be beneficial to help their firm find suitable partners [103]. Hence, from a strategic perspective, it may be wise for businesses to change from being opportunistic organizations (i.e., reacting to NPOs' offerings) to being strategic organizations (i.e., designing collaboration proactively in seeking prospective partners) [13]. Second, relational factors are the most important predictors of partnership success. Indeed, partner characteristics impact partnership success only because they are positively related to the relational capital. Therefore, developing trust, information sharing, and commitment is indispensable to the success of business-nonprofit partnerships. We would recommend that managers who wish to improve the success of their partnering processes need to be honest and sincere, avoiding, in particular, making false statements, to engage in regular communication with their nonprofit partners and to dedicate the maximum effort and resources to maintain the relationship into the future. The success of their partnership processes with NPOs depends to a large extent on the investment that business managers make in building highquality relationships with those organizations.

It is our hope that the present study may encourage practitioners to set up social partnerships of greater effectiveness through collaboration agreements with suitable partners and to establish practices of relationship management that allow the partners to benefit from frequent, high-quality interactions.

Nevertheless, every research study has certain limitations that affect the generalizability of its results and which open up new avenues for future research. There are three main limitations in our work. First, our research defined the target population to be those "Spanish businesses in cross-sector collaboration relationships with nonprofit organizations in recent years." This limits the generalizability of the results to not going beyond the context actually analysed. Future studies might confirm the proposed success model using their sample 
businesses in cross-sector collaboration relationships which are based in other countries. Second, in our work, we validate the proposed research model with a total sample of 102 observations. Although the sample size is adequate for the use of the statistical technique used, PLS, future studies could replicate the proposed model using a sample with a greater number of observations and also evaluate the model from a dynamic perspective, addressing the temporal aspect of the relationships analysed. And, third, in order to validate the proposed model, we used only data from the perceptions of just one of the two partners involved in these associations-the businesses. In this sense, it would be interesting if other studies could validate the proposed model using data from the perceptions of the other partner involved in these associative processes-the NPOs.

\section{Data Availability}

The data used to support the findings of this study are available from the corresponding author upon request.

\section{Conflicts of Interest}

The authors declare that there are no conflicts of interest.

\section{Acknowledgments}

This research was cofinanced by the Extremadura Regional Government and the European Regional Development Fund (FEDER) (code GR18027).

\section{References}

[1] F. Den Hond, F. G. A. de Bakker, and J. Doh, "What prompts companies to collaboration with NGOs? recent evidence from The Netherlands," Business \& Society, vol. 54, no. 2, pp. 187-228, 2015.

[2] S. McDonald and S. Young, "Cross-sector collaboration shaping corporate social responsibility best practice within the mining industry," Journal of Cleaner Production, vol. 37, pp. 54-67, 2012.

[3] D. Jamali and T. Keshishian, "Uneasy alliances: lessons learned from partnerships between businesses and NGOs in the context of CSR," Journal of Business Ethics, vol. 84, no. 2, pp. 277-295, 2009.

[4] R. Gutiérrez, J. Schmutzler, P. Márquez, and C. Reficco, "Survival and demise of alliances within a Portfolio to develop an inclusive business," in Proceedings of the 3rd International Symposium about Cross Sector Social Interactions, Rotterdam, The Netherlands, May 2012.

[5] M. J. Barroso-Méndez, C. Galera-Casquet, M. M. Seitanidi, and V. Valero-Amaro, "Cross-sector social partnership success: a process perspective on the role of relational factors," European Management Journal, vol. 34, no. 6, pp. 674-685, 2016.

[6] S. Sherman, "Are strategic alliances working?" Fortune, vol. 126, no. 6, pp. 77-78, 1992.

[7] J. E. Austin and M. M. Seitanidi, "Collaborative value creation. A review of partnering between 695 nonprofits and businesses. Part 2: partnership processes and outcomes," Nonprofit and Voluntary Sector Quarterly, vol. 41, no. 6, pp. 929-968, 2012.

[8] J. A. Rodríguez, C. Giménez, and D. Arenas, "Cooperative initiatives with NGOs in socially sustainable supply chains: how is inter-organizational fit achieved?" Journal of Cleaner Production, vol. 137, pp. 516-526, 2016.

[9] M. Shumate, Y. P. Hsieh, and A. O'Connor, “A nonprofit perspective on business-nonprofit partnerships: extending the symbiotic sustainability model," Business \& Society, vol. 57, no. 7, pp. 1337-1373, 2016.

[10] J. E. Austin and M. M. Seitanidi, Creating Value in NonprofitBusiness Collaborations: New Thinking and Practice, John Wiley \& Sons, San Francisco, CA, USA, 2014.

[11] G. Harangozó and G. Zilahy, "Cooperation between business and non-governmental organizations to promote sustainable development," Journal of Cleaner Production, vol. 89, pp. 18-31, 2015.

[12] L. I. Álvarez-González, N. García-Rodríguez, M. Rey-García, and M. J. Sanzo-Perez, "Business-nonprofit partnerships as a driver of internal marketing in nonprofit organizations. Consequences for nonprofit performance and moderators," BRQ Business Research Quarterly, vol. 20, no. 2, pp. 112-123, 2017.

[13] O. Al-Tabbaa, D. Leach, and Z. Khan, "Examining alliance management capabilities in cross-sector collaborative partnerships," Journal of Business Research, vol. 101, pp. 268-284, 2019.

[14] D. Jamali, M. Yianni, and H. Abdallah, "Strategic partnerships, social capital and innovation: accounting for social alliance innovation," Business Ethics: A European Review, vol. 20, no. 4, pp. 375-391, 2011.

[15] M. M. Seitanidi, The Politics of Partnerships. A Critical Examination of Nonprofit-Business Partnerships, Springer, London, UK, 2010.

[16] M. Murphy, D. Arenas, and J. M. Batista, "Value creation in cross-sector collaborations: the roles of experience and alignment," Journal of Business Ethics, vol. 130, no. 1, pp. 145-162, 2015.

[17] M. J. Sanzo, L. I. Álvarez, M. Rey, and N. García, "Businessnonprofit partnerships: do their effects extend beyond the charitable donor-recipient model?" Nonprofit and Voluntary Sector Quarterly, vol. 44, no. 2, pp. 379-400, 2015.

[18] M. J. Sanzo, L. I. Alvarez, and M. Rey, "Lights and shadows of business-nonprofit partnerships: the role of nonprofit learning and empowerment in this ethical puzzle," Sustainability, vol. 9, pp. 1-21, 2017.

[19] C. Weber, K. Weidner, A. Kroeger, and J. Wallace, "Social value creation in inter-organizational collaborations in the not-for-profit sector-give and take from a dyadic perspective," Journal of Management Studies, vol. 54, no. 6, pp. 929-956, 2017.

[20] Y. C. Atouba and M. D. Shumate, "Meeting the challenge of effectiveness in nonprofit partnerships: examining the roles of partner selection, trust, and communication," International Journal of Voluntary and Nonprofit Organizations, vol. 31, pp. 301-315, 2020.

[21] H. Lin and N. Darnall, "Strategic alliance formation and structural configuration," Journal of Business Ethics, vol. 127, no. 3, pp. 549-564, 2015.

[22] A. Lyakhov and T. Gliedt, "Understanding collaborative value creation by environmental nonprofit and renewable energy business partnerships," VOLUNTAS: International Journal of Voluntary and Nonprofit Organizations, vol. 28, no. 4, pp. 1448-1472, 2017.

[23] N. M. Dahan, J. P. Doh, J. Oetzel, and M. Yaziji, “CorporateNGO collaboration: co-creating new business models for developing markets," Long Range Planning, vol. 43, no. 2-3, pp. 326-342, 2010. 
[24] A. Kolk, W. Van Dolen, and M. Vock, "Trickle effects of cross-sector social partnerships," Journal of Business Ethics, vol. 94, no. 1, pp. 123-137, 2010.

[25] J. E. Austin, "From organization to organization: on creating value," Journal of Business Ethics, vol. 94, no. 1, pp. 13-15, 2010.

[26] M. J. Barroso-Méndez, C. Galera-Casquet, V. Valero-Amaro, and M. T. Nevado-Gil, "Antecedents of relationship learning in business-non-profit organization collaboration agreements," Sustainability, vol. 12, no. 1, p. 269, 2020.

[27] A. Parkhe, "Strategic alliance structuring: a game theoretic and transaction cost examination of interfirm cooperation," Academy of Management Journal, vol. 36, no. 4, pp. 794-829, 1993.

[28] P. S. Aulakh, M. Kotabe, and A. Sahay, "Trust and performance in cross-border marketing partnerships: a behavioral approach," Journal of International Business Studies, vol. 27, no. 5, pp. 1005-1032, 1996.

[29] J. B. Heide and S. Miner, "The shadow of the future: effects of anticipated interaction and frequency of contact on buyerselling cooperation," Academy of Management Journal, vol. 35, no. 6, pp. 265-291, 1992.

[30] J. B. Cullen, J. L. Johnson, and T. Sakano, "Success through commitment and trust: the soft side of strategic alliance management," Journal of World Business, vol. 35, no. 3, pp. 223-240, 2000.

[31] M. Sarkar, R. Echambadi, S. T. Cavusgil, and P. S. Aulakh, "The influence of complementarity, compatibility, and relationship capital on alliance performance," Journal of the Academy of Marketing Science, vol. 29, no. 4, pp. 358-373, 2001.

[32] C. Tser-Yieth, L. Hsiang-His, and H. Wei-Lan, "The influence of partner characteristics and relationship capital on the performance of international strategic alliances," Journal of Relationship Marketing, vol. 8, no. 3, pp. 231-252, 2009.

[33] K. Moeller, "Partner selection, partner behavior, and business network performance: an empirical study on German business networks," Journal of Accounting \& Organizational Change, vol. 6, no. 1, pp. 27-51, 2010.

[34] M. Sambasivan, L. Siew-Phaik, Z. Abidin Mohamed, and Y. Choy Leong, "Factors influencing strategic alliance outcomes in a manufacturing supply chain: role of alliance motives, interdependence, asset specificity and relational capital," International Journal of Production Economics, vol. 141, no. 1, pp. 339-351, 2013.

[35] S. D. Jap, "Pie-expansion efforts: collaboration processes in buyer-supplier relationships," Journal of Marketing Research, vol. 36, no. 4, pp. 461-475, 1999.

[36] T. Gao and L. H. Shi, "How do multinational suppliers formulate mechanisms of global account coordination? an integrative framework and empirical study," Journal of International Marketing, vol. 19, no. 4, pp. 61-87, 2011.

[37] M. J. Robson, C. S. Katsikeas, B. B. Schlegelmilch, and B. Pramböck, "Alliance capabilities, interpartner attributes, and performance outcomes in international strategic alliances," Journal of World Business, vol. 54, no. 2, pp. 137-153, 2019.

[38] R. M. Morgan and S. D. Hunt, "The commitment-trust theory of relationship marketing," Journal of Marketing, vol. 58, no. 3, pp. 20-38, 1994.

[39] S. Madhavaram and S. D. Hunt, "Customizing business-tobusiness (B2B) professional services: the role of intellectual capital and internal social capital," Journal of Business Research, vol. 74, pp. 38-46, 2017.
[40] K. MacMillan, K. Money, A. Money, and S. Downing, "Relationship marketing in the not-for-profit sector: an extension and application of the commitment-trust theory," Journal of Business Research, vol. 58, no. 6, pp. 806-818, 2005.

[41] M. Y. Wu, Y. C. Weng, and I. C. Huang, "A study of supply chain partnerships based on the commitment-trust theory," Asia Pacific Journal of Marketing and Logistics, vol. 24, no. 4, pp. 690-707, 2012.

[42] H. Akrout and M. F. Diallo, "Fundamental transformations of trust and its drivers: a multi-stage approach of businessto-business relationships," Industrial Marketing Management, vol. 66, pp. 159-171, 2017.

[43] M. Rivera-Santos and C. Rufín, "Odd couples: understanding the governance of firm-NGO alliances," Journal of Business Ethics, vol. 94, no. 1, pp. 55-70, 2010.

[44] P. Glasbergen, "Understanding partnerships for sustainable development analytically: the ladder of partnership activity as a methodological tool," Environmental Policy and Governance, vol. 21, no. 1, pp. 1-13, 2011

[45] N. Graf and F. Rothlauf, "Firm-NGO collaborations: a resource-based perspective," Zeitschrift für Betriebswirtschaft, vol. 82, no. 6, pp. 103-125, 2012.

[46] E. Anderson and B. Weitz, "The use of pledges to build and sustain commitment in distribution channels," Journal of Marketing Research, vol. 29, no. 1, pp. 18-34, 1992.

[47] L. Zhang, J. Wang, and W. C. Poon, "Research on the relationship between relational capital and relational rent," Cogent Economics \& Finance, vol. 6, no. 1, Article ID 1431091, 2018.

[48] X. Guo, A. Duff, and M. Hair, "The antecedents and consequences of commitment in bank-corporate relationships: evidence from the Chinese banking market," Asia Pacific Business Review, vol. 16, no. 3, pp. 395-416, 2010.

[49] B. Čater, V. Žabkar, and T. Čater, "Commitment in marketing research services: two alternative models," Journal of Business Economics and Management, vol. 12, no. 4, pp. 603-628, 2011.

[50] J. C. Anderson and J. A. Narus, "A model of distributor firm and manufacturer firm working partnerships," Journal of Marketing, vol. 54, no. 1, pp. 42-58, 1990.

[51] C. Moorman, R. Deshpandé, and G. Zaltman, "Factors affecting trust in market research relationships," Journal of Marketing, vol. 57, no. 1, pp. 81-101, 1993.

[52] I. Geyskens, J.-B. E. M. Steenkamp, and N. Kumar, "Generalizations about trust in marketing channel relationships using meta-analysis," International Journal of Research in Marketing, vol. 15, no. 3, pp. 223-248, 1998.

[53] B. Ashnai, S. C. Henneberg, P. Naudé, and A. Francescucci, "Inter-personal and inter-organizational trust in business relationships: an attitude-behavior-outcome model," Industrial Marketing Management, vol. 52, pp. 128-139, 2016.

[54] P. M. Doney, J. M. Barry, and R. Abratt, "Trust determinants and outcomes in global B2B services," European Journal of Marketing, vol. 41, no. 9/10, pp. 1096-1116, 2007.

[55] J. R. Segarra, M. A. Moliner, and J. Sánchez, "Relationship quality in business to business: a cross-cultural perspective from universities," Marketing Intelligence \& Planning, vol. 31, no. 3, pp. 196-215, 2013.

[56] J. P. Cannon and W. D. Perreault, "Buyer-seller relationships in business markets," Journal of Marketing Research, vol. 36, no. 4, pp. 439-460, 1999.

[57] X. Su, H. Zhang, and S. Guo, "A model and complexity analysis of the relationship based on organizational justice 
and embeddedness theories," Complexity, vol. 2020, Article ID 6129840, 16 pages, 2020.

[58] J. Goo and C. D. Huang, "Facilitating relational governance through service level agreements in IT outsourcing: an application of the commitment-trust theory," Decision Support Systems, vol. 46, no. 1, pp. 216-232, 2008.

[59] H. Y. Ha, "Alternative explanations of business-to-business relationships: the relational case between web-based companies and traditional channel partners in South Korea," Asian Business \& Management, vol. 9, no. 1, pp. 149-171, 2010.

[60] C. M. Wittmann, S. D. Hunt, and D. B. Arnett, "Explaining alliance success: competences, resources, relational factors, and resource-advantage theory," Industrial Marketing Management, vol. 38, no. 7, pp. 743-756, 2009.

[61] S. S. Graça and J. M. Barry, "A global examination of cognitive trust in business-to-business relationships," New Insights on Trust in Business-to-Business Relationships, vol. 26, pp. 7-36, 2019.

[62] A. Lancastre and L. F. Lages, "The relationship between buyer and a B2B e-marketplace: cooperation determinants in an electronic market context," Industrial Marketing Management, vol. 35, no. 6, pp. 774-789, 2006.

[63] M. J. Le Ber and O. Branzei, "(Re)Forming strategic crosssector partnerships: relational processes of social innovation,” Business \& Society, vol. 49, no. 1, pp. 140-172, 2010.

[64] P. A. McDaniel and R. E. Malone, "British American tobacco's partnership with earthwatch Europe and its implications for public health," Global Public Health, vol. 7, no. 1, pp. 14-28, 2012.

[65] J. Arenas and R. García, "La aportación relacional al éxito de las alianzas estratégicas internacionales," Revista Española de Investigación de Marketing, vol. 10, no. 2, pp. 139-161, 2006.

[66] S. Kauser and V. Shaw, "The influence of behavioural and organisational characteristics on the success of international strategic alliances," International Marketing Review, vol. 21, no. 1, pp. 17-52, 2004.

[67] J. Mohr and R. Spekman, "Characteristics of partnership success: partnership attributes, communication behavior, and conflict resolution techniques," Strategic Management Journal, vol. 15, no. 2, pp. 135-152, 1994.

[68] S. D. Hunt, C. J. Lambe, and C. M. Wittmann, "A theory and model of business alliance success," Journal of Relationship Marketing, vol. 1, no. 1, pp. 17-35, 2002.

[69] J. Henseler, C. M. Ringle, and M. Sarstedt, "Testing measurement invariance of composites using partial least squares," International Marketing Review, vol. 33, no. 3, pp. 405-431, 2016.

[70] J. Henseler, T. K. Dijkstra, M. Sarstedt et al., "Common beliefs and reality about PLS: comments on Rönkkö and Evermann (2013)," Organizational Research Methods, vol. 17, no. 2, pp. 182-209, 2014.

[71] J. Henseler, "Bridging design and behavioral research with variance-based structural equation modeling," Journal of Advertising, vol. 46, no. 1, pp. 178-192, 2017.

[72] R. Vázquez, V. Iglesias, and L. I. Á \& siasGonzález, "Distribution channel relationships: the conditions and strategic outcomes of cooperation between manufacturer and distributor," The International Review of Retail, Distribution and Consumer Research, vol. 15, no. 2, pp. 125-150, 2005.

[73] F. Selnes and J. Sallis, "Promoting relationship learning," Journal of Marketing, vol. 67, no. 3, pp. 80-95, 2003.

[74] J. J. Cambra and Y. Polo, "Long-term orientation of the supply function in the SME context: reasons, determining factors and implications," International Small Business Journal, vol. 26, no. 5, pp. 619-646, 2008.

[75] S. B. MacKenzie, P. M. Podsakoff, and C. B. Jarvis, "The problem of measurement model misspecification in behavioral and organizational research and some recommended solutions," Journal of Applied Psychology, vol. 90, no. 4, pp. 710-730, 2005.

[76] I. Castro, J. L. Roldán, and F. J. Acedo, "The dimensions of alliance portfolio configuration: a mediation model," Journal of Management \& Organization, vol. 21, no. 2, pp. 176-202, 2015.

[77] W. W. Chin and P. R. Newsted, "Structural equation modeling analysis with small samples using partial least squares," Statistical Strategies for Small Sample Research, vol. 1, no. 1, pp. 307-341, 1999.

[78] J. L. Roldán and M. J. Sánchez-Franco, "Variance-based structural equation modeling: guidelines for using partial least squares in information systems research," in Research Methodologies, Innovations and Philosophies in Software Systems Engineering and Information Systems, M. Mora, O. Gelman, A. Steenkamp, and M. S. Raisinghani, Eds., pp. 193-221, Information Science Reference, Hershey, PA, USA, 2012.

[79] J. F. J. Hair, G. T. M. Hult, C. M. Ringle, and M. Sarstedt, $A$ Primer on Partial Least Squares Structural Equation Modeling (PLS-SEM), SAGE Publications, Thousand Oaks, CA, USA, 2nd edition, 2017.

[80] A. Mosquera, E. Juaneda-Ayensa, C. Olarte-Pascual, and J. Pelegrín-Borondo, "Key factors for in-store smartphone use in an omnichannel experience: millennials vs. nonmillennials," Complexity, vol. 2018, Article ID 1057356, 14 pages, 2018.

[81] J. F. Hair, C. M. Ringle, and M. Sarstedt, "PLS-SEM: indeed a silver bullet," Journal of Marketing Theory and Practice, vol. 19, no. 2, pp. 139-152, 2011.

[82] D. Barclay, R. Thompson, and Ch. Higgins, "The partial least squares (PLS) approach to causal modeling: personal computer adoption and use as an illustration," Technology Studies, vol. 22, no. 2, pp. 285-309, 1995.

[83] N. Kock, "Common method bias: a full collinearity assessment method for PLS-SEM," in Partial Least Squares Path Modeling, H. Latan and R. Noonan, Eds., pp. 245-257, Springer, Cham, Switzerland, 2017.

[84] P. M. Podsakoff, S. B. MacKenzie, and N. P. Podsakoff, "Sources of method bias in social science research and recommendations on how to control it," Annual Review of Psychology, vol. 63, no. 1, pp. 539-569, 2012.

[85] N. Kock, "Common method bias in PLS-SEM: a full collinearity assessment approach," International Journal of e-Collaboration, vol. 11, no. 4, pp. 1-10, 2015.

[86] J. R. Díaz-Reza, J. L. García-Alcaraz, J. R. Mendoza-Fong, V. Martínez-Loya, E. J. Macías, and J. Blanco-Fernández, "Interrelations among SMED stages: a causal model," Complexity, vol. 2017, Article ID 5912940, 10 pages, 2017.

[87] N. Rubio, N. Villaseñor, and M. J. Yague, "Does use of different platforms influence the relationship between cocreation value-in-use and participants' cocreation behaviors? an application in third-party managed virtual communities," Complexity, vol. 2019, Article ID 7562903, 15 pages, 2019.

[88] R. Robina-Ramírez, A. Fernández-Portillo, and J. C. DíazCasero, "Green start-ups' attitudes towards nature when complying with the corporate law," Complexity, vol. 2019, Article ID 4164853, 17 pages, 2019. 
[89] E. G. Carmines and R. A. Zeller, Reliability and Validity Assessment, Sage Publications, Inc, Newbury Park, CA, USA, 1979.

[90] W. W. Chin, "The partial least squares approach to structural equation modeling," in Modern Methods for Business Research, G. A. Marcoulides, Ed., pp. 295-336, Lawrence Erlbaum, Mahwah, NJ, USA, 1998.

[91] J. C. Nunnally and I. H. Bernstein, Psychometric Theory, McGraw-Hill, New York, NY, USA, 3rd edition, 1994.

[92] C. Fornell and D. F. Larcker, "Evaluating structural equation models with unobservable variables and measurement error," Journal of Marketing Research, vol. 18, no. 1, pp. 39-50, 1981.

[93] J. M. Berbel-Pineda, B. Palacios-Florencio, L. Santos-Roldán, and J. M. Ramírez Hurtado, "Relation of country-of-origin effect, culture, and type of product with the consumer's shopping intention: an analysis for small-and medium-sized enterprises," Complexity, vol. 2018, Article ID 8571530, 12 pages, 2018.

[94] P. Palos-Sanchez, F. Martin-Velicia, and J. R. Saura, "Complexity in the acceptance of sustainable search engines on the internet: an analysis of unobserved heterogeneity with FIMIX-PLS," Complexity, vol. 2018, Article ID 6561417, 19 pages, 2018.

[95] W. W. Chin, "How to write up and report PLS analyses," in Handbook of Partial Least Squares: Concepts, Methods and Applications, V. Esposito Vinzi, W. W. Chin, J. Henseler, and H. Wang, Eds., pp. 655-690, Springer, Berlin, Germany, 2010.

[96] L. T. Hu and P. M. Bentler, "Cutoff criteria for fit indexes in covariance structure analysis: conventional criteria versus new alternatives," Structural Equation Modeling: A Multidisciplinary Journal, vol. 6, no. 1, pp. 1-55, 1999.

[97] P. M. Bentler and D. G. Bonett, "Significance tests and goodness of fit in the analysis of covariance structures," Psychological Bulletin, vol. 88, no. 3, pp. 588-606, 1980.

[98] G. Shmueli and O. R. Koppius, "Predictive analytics in information systems research," MIS Quarterly: Management Information Systems, vol. 35, no. 3, pp. 553-572, 2011.

[99] M. Sarstedt, C. M. Ringle, G. Schmueli, J. H. Cheah, and H. Ting, "Predictive model assessment in PLS-SEM: guidelines for using PLSpredict," European Journal of Marketing, vol. 53, no. 11, pp. 2322-2347, 2018.

[100] C. M. Ringle, S. Wende, and J. M. Becker, SmartPLS3, SmartPLS GmbH, Boenningstedt, Germany, 2015, http:// www.smartpls.com.

[101] C. M. Felipe, J. L. Roldán, and A. L. Leal-Rodríguez, "Impact of organizational culture values on organizational agility," Sustainability, vol. 9, no. 12, p. 2354, 2017.

[102] R. Tennyson, The Partnering Toolbook, International Business Leaders Forum, London, UK, 2003.

[103] Y. Su and T. Li, "Simulation analysis of knowledge transfer in a knowledge alliance based on a circular surface radiator model," Complexity, vol. 2020, Article ID 4301489, 27 pages, 2020 . 